\title{
FERRAMENTAS VIRTUAIS DE AUXÍLIO NO TRANSPORTE: TESTE DE USABILIDADE DE UM APLICATIVO PARA CICLISTAS DA UFMA
}

\section{VIRTUAL TOOLS AID IN TRANSPORTATION: USABILITY TEST OF AN APPLICATION FOR CYCLISTS FROM UFMA}

\author{
Rubenio dos Santos Barros ${ }^{1}$, Bel. \\ Moisaniel Pimentel Filho², Bel. \\ Lívia Flávia de Albuquerque Campos ${ }^{3}$, D.Sc. \\ (1) Universidade Federal do Maranhão \\ e-mail: rubeniobarros@hotmail.com \\ (2) Universidade Federal do Maranhão \\ e-mail:moisa_filho@hotmail.com

\section{(3) Universidade Estadual Paulista Júlio de Mesquita Filho e-mail: liviaflavia@gmail.com}

Aplicativo, usabilidade, design participativo

\begin{abstract}
Este artigo apresenta o desenvolvimento de uma proposta de aplicativo que visa oferecer suporte e incentivar a adoção do ciclismo como meio de transporte entre estudantes da Universidade Federal do Maranhão, tendo como foco o design participativo e a usabilidade. São apresentadas as etapas de projetação, tendo destaque princípios ergonômicos ao longo do processo. Ao final, desenvolveu-se um teste de usabilidade com a ferramenta SUS a partir de um protótipo funcional do aplicativo que apresentou índice de satisfação e usabilidade 93,33 entre os participantes.
\end{abstract}

App, usability, participatory design

This article presents the development of an application proposal that aims to support and encourage the adoption of cycling as a means of transportation among students of the Federal University of Maranhão, focusing on participatory design and usability. The stages of design are presented, focusing on ergonomic principles throughout the process. At the end, a usability test was developed with the SUS tool with a functional prototype of the application which presented satisfaction and usability index 93.33 among the participants.

\section{Introdução}

O panorama caótico de grandes cidades no que diz respeito à locomoção é bastante conhecido e um dos grandes gargalos de infraestrutura no Brasil. A valorização exacerbada do automóvel acaba por sobrecarregar a malha viária das cidades e que, em conjunto com um sistema de transporte público deficitário, acarreta em longas horas de congestionamentos, estresse, perda de qualidade de vida e ainda perda para a economia resultante do custo de produção sacrificada, que é o impacto das longas viagens de casa até o trabalho, sendo superior a $\mathrm{R} \$ 111$ bilhões em todo o território brasileiro (FIRJAN, 2015a).

Em São Luís essa realidade também pode ser observada, onde até mesmo pequenos trajetos podem resultar em desconforto em horários de pico. De acordo com dados do Sistema Firjan (2015b), entre 2011 e 2012 houve um aumento no tempo médio gasto no deslocamento na área metropolitana de São Luís de 2,1\%, indo de 116 para 118 minutos gastos no trajeto casa-trabalho-casa. E o número de 


\section{$16^{\circ}$ \\ ERGODESIGN USIHC CINAHPA}

$16^{\circ}$ Ergodesign - Congresso Internacional de Ergonomia e Usabilidade de Interfaces Humano Tecnológica: Produto, Informações Ambientes Construídos e Transporte

$16^{\circ}$ USIHC - Congresso Internacional de Ergonomia e Usabilidade de Interfaces Humano Computador

CINAHPA | 2017 - Congresso Internacional de Ambientes Hipermídia para Aprendizagem. trabalhadores com deslocamento acima de 30 minutos passou de 254.830 para 257.177 no mesmo período.

Dentro desse complexo conjunto que compõe o atual sistema de transporte, uma vertente vem gradativamente adquirindo uma parcela cada vez maior nessa equação, atraindo um número cada vez mais expressivo de usuários. $\mathrm{O}$ transporte por meio da bicicleta é bem mais cômodo e agradável do que os quase sempre lotados ônibus, cobrindo eficientemente pequenas distâncias, pois possui uma liberdade maior que os demais veículos e, como afirma a Confederação Nacional da Indústria - CNI (2010), em trajetos de até $10 \mathrm{~km}$, a bicicleta é mais rápida que o carro, principalmente nos horários mais movimentados. Junto a isso, o uso da bicicleta tem um custo consideravelmente reduzido se comparado aos carros e até mesmo em relação ao transporte público, pois é gratuito (CNI, 2010).

Para melhor usufruir das possibilidades e benefícios desse meio de transporte, os usuários tendem a procurar ferramentas e informações que facilitem este processo. Dentre as ferramentas estão as redes sociais, que têm se consolidado como uma forma de comunicação, colaboração e trabalhos on-line, além de estarem sendo apropriadas aos ambientes de trabalho e educação (LINDNER, ULBRICHT, PALAZZO, 2015).

Apesar do grande conteúdo gerado nesses meios, ainda há uma generalização e diversidades de temas, que são constantes e causam uma sensação de dispersão durante a navegação. Dessa forma, surgiram as redes sociais temáticas, que são ferramentas virtuais construídas em torno de um tema principal e assim como as redes sociais comuns, possuem diversos recursos como fóruns, chats, feeds de notícias, galerias, grupos, etc. (LINDNER, ULBRICHT, PALAZZO, 2015).

Com o tema definido, os participantes possuem um foco de conteúdo, e a partir disso, promovem a geração e compartilhamento de conhecimento a outros usuários. Ferramentas virtuais como essas se tornam fundamentais para a facilitação ou até mesmo a resolução de problemas específicos. Logo, nichos restritos como os ciclistas de São Luís, sobretudo os ciclistas da Universidade Federal do
Maranhão - UFMA, podem usufruir destas ferramentas como um suporte colaborativo relacionados ao ciclismo da cidade.

Para efetuar esta interação, a boa usabilidade da interface é primordial e, de acordo com Lindner, Ulbricht, Palazoo (2015), isto vem desde o acesso à informação até a possibilidade de contribuir, gerar e controlar conteúdos proporcionados nesses meios. Os autores ainda apontam que as interfaces de algumas redes sociais temáticas buscam apropriar-se do repertório pessoal do usuário ao buscarem referências nas redes sociais massivas. Isto está intrinsecamente relacionado com as memórias de longa duração, que de acordo com lida e Buarque (2016), tem caráter associativo, ou seja, as novas informações são mais fáceis de serem fixadas quando estão conectadas a memórias (referências) já existentes. Além disso, Iida e Buarque (2016) apontam outras recomendações de projetação para resultar em uma boa usabilidade em interfaces digitais, sendo estas: a) atender as expectativas da maioria dos usuários; b) apresentar consistência; c) facilitar a operação manual; d) fornecer feedbacks imediatos e frequentes; e) evitar sobrecargas e f) permitir o uso universal.

Dessa forma, o presente artigo visa explorar o panorama do ciclismo na cidade, sobretudo na UFMA, apresentando uma proposta de ferramenta virtual colaborativa, respeitando os princípios de usabilidade. Para o desenvolvimento do aplicativo, utilizou-se a abordagem participativa onde a partir da inclusão dos usuários no processo de projetação, objetivou-se a eficiência da ferramenta.

\section{O ciclismo na UFMA}

O que acontece na cidade também reflete no interior do Campus. Quando se analisa o panorama do uso da bicicleta na UFMA, observa-se que a presença de alunos e funcionários que utilizam esse meio de transporte no seu translado ainda é tímida, apesar de uma parcela considerável residir em bairros dentro do raio de deslocamento aceitável e favorável de até $10 \mathrm{~km}$ indicado pelo CNI (2010) para o uso da bicicleta, como mostra a Figura 1 . 


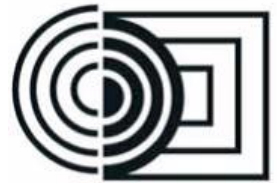

$16^{\circ}$ Ergodesign - Congresso Internacional de Ergonomia e Usabilidade de Interfaces Humano Tecnológica: Produto, Informações Ambientes Construídos e Transporte

$16^{\circ}$ USIHC - Congresso Internacional de Ergonomia e Usabilidade de Interfaces Humano Computador

CINAHPA | 2017 - Congresso Internacional de Ambientes Hipermídia para Aprendizagem.

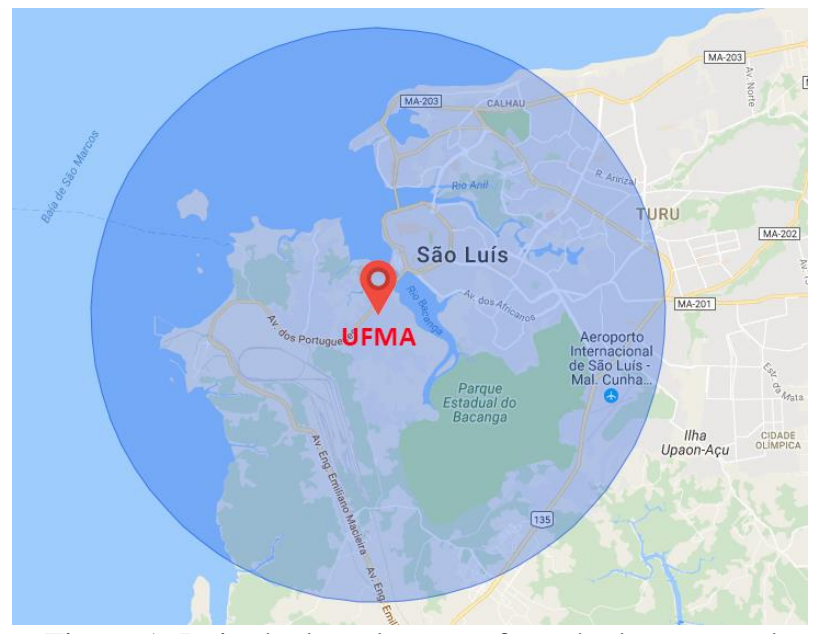

Figura 1: Raio de descolamento favorável para uso de bicicleta como meio de transporte.

Fonte: Gmaps-radius, (2017)

A utilização da bicicleta dentro do Campus também é dificultada pela falta de estrutura, como a ausência de faixas específicas, ciclovias, bicicletários e sinalização adequada. Apesar de surgirem iniciativas que incentivem o ciclismo dentro do campus ou como forma de transporte até a cidade universitária, esses projetos não chegam até a fase de implantação, podendo ser citado como exemplo o estudo desenvolvido por Reis (2014), que apresentava um planejamento estratégico de infraestrutura acerca do uso de bicicletas na cidade universitária.

Desta forma, desenvolver iniciativas em uma atmosfera virtual pode contornar ou auxiliar na elucidação de alguns dos empecilhos que dificultam a rotina dos estudantes ciclistas e de outros indivíduos que desejam utilizar a bicicleta na locomoção.

\section{Aplicativos para ciclistas}

Atualmente existem inúmeros aplicativos que auxiliam no uso das bicicletas para as mais variadas finalidades, oferecendo alguma forma de suporte que abrange desde o uso de bicicletas exclusivamente como forma de lazer até o âmbito profissional, como é o caso do Strava, que apresenta várias funcionalidades para monitorar a atividade dos ciclistas e fornecer os mais diversos tipos de ferramentas com alta integração e conectividade. Há aplicativos que oferecem suporte desde a elaboração do trajeto mais adequado, na análise do tempo a ser gasto, a quantidade de calorias consumidas (como exemplo, os aplicativos Ride With GPS, Bikemap, Urban Biker e Bike Activity) e até mesmo sobre como realizar reparos, facilitando consideravelmente a experiência do ciclismo, como é o caso dos aplicativos Bike Repair e Bike Doctor. A seguir, a Figura 2 apresenta alguns dos aplicativos voltados para ciclistas.
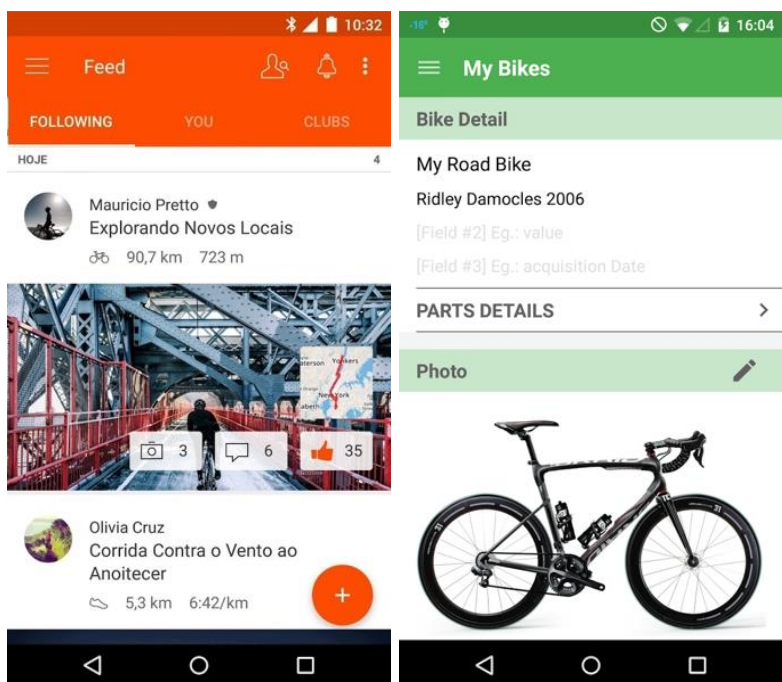

$$
\text { Ridley Damocles } 2006
$$
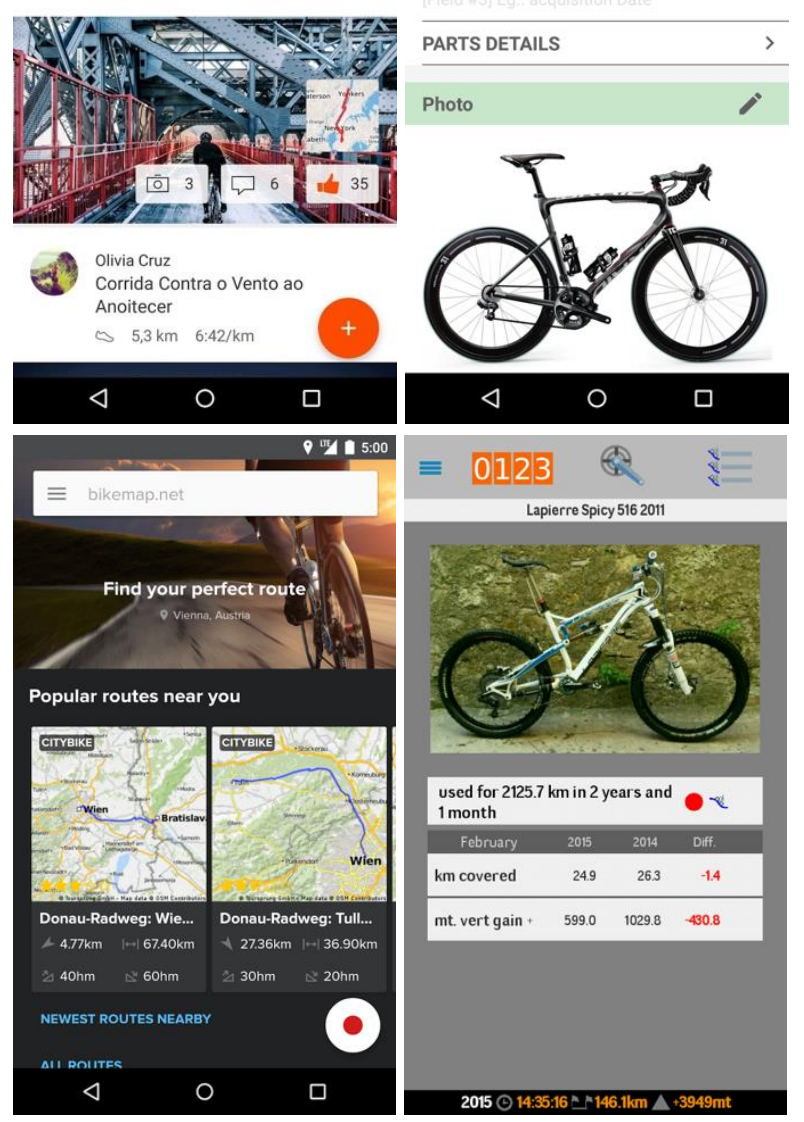

Figura 2: Exemplos de aplicativos voltados para ciclistas. Fonte: Google Play (2017).

Desta forma, a utilização dessas ferramentas indubitavelmente traz mais praticidade e conforto ao ciclista, sendo que o uso desses aplicativos vem se tornando cada vez mais frequente, dado o aumento no número de ciclistas em escala global. Um elemento que é fortemente presente na grande maioria desses aplicativos é a capacidade de 
$16^{\circ}$ Ergodesign - Congresso Internacional de Ergonomia e Usabilidade de Interfaces Humano Tecnológica: Produto, Informações Ambientes Construídos e Transporte

$16^{\circ}$ USIHC - Congresso Internacional de Ergonomia e Usabilidade de Interfaces Humano Computador

conectividade e integração com outros serviços e plataformas digitais, mais especificamente com as redes sociais, possibilitando maior o

compartilhamento e cruzamento de informações em tempo real acerca das atividades executadas, como em relação ao trajeto realizado, o tempo gasto, o levantamento dos demais indivíduos que realizaram o mesmo trajeto, dentre outros.

\section{Design participativo para aplicativos}

Visto a importância de uma interação eficiente e agradável para os usuários de aplicativos, incluindo os voltados para ciclistas, a abordagem do design participativo, na qual os usuários têm papel ativo e alto envolvimento no projeto, é adotada no intuito de melhorar a qualidade do sistema, evitar a implementação de funções sem utilidades, apresentar relação custo/benefício elevado, aumentar o nível de aceitação e propiciar o uso mais efetivo daquilo que é proposto (MORAES E SANTA ROSA, 2012).

Esse pensamento é confirmado através dos estudos desenvolvidos por Guimarães (2010), que destacam o design participativo como eficiente, vantajoso e que os esforços investidos nessa experiência são recompensados no final. Para a autora, o design participativo, junto com a ergonomia, leva a soluções mais adaptadas e, portanto, colocadas em prática com aceitação.

Sobre o tema, Spinuzzi (2005, tradução nossa) acrescenta que o design participativo busca nos usuários, ao qual se deseja projetar algo, o conhecimento tácito e frequentemente invisível obtido a partir das atividades diárias desempenhadas por esses usuários, conhecimento esse que pode ser moldado produtivamente, se tornando uma fonte rica de informações.

A inclusão do usuário durante o processo de desenvolvimento de uma interface, o que é garantido através do design participativo, tem impacto direto na usabilidade do sistema. Como afirmam Cybis, Betiol e Faust (2007):

A construção de um sistema com usabilidade depende da análise cuidadosa dos diversos componentes de seu contexto de uso e da participação ativa do usuário nas decisões de projeto da interface, visto como o processo de configuração de qualidades internas e externas do sistema.

Assim, dentro de um projeto o designer ou equipe de design pode se beneficiar da aproximação e participação dos usuários nos mais diversos âmbitos, desde as fases iniciais, onde podem ser coletadas e filtradas informações de delineamento e compreensão da demanda, até as etapas finais como a realização de testes de usabilidade, tendo uma visão mais precisa e condizente com a realidade (GUIMARÃES, 2010).

\section{Proposta de aplicativo: Dínamo}

A partir dos panoramas, as possibilidades e as necessidades dos usuários, este artigo apresenta uma proposta de um aplicativo que dê suporte e incentive o uso da bicicleta como meio de transporte aos estudantes e funcionários da Universidade Federal do Maranhão, tendo destaque no uso colaborativo entre os usuários para fomento do aplicativo e para o fortalecimento da comunidade ciclista.

\section{Métodos e técnicas}

Para a elaboração do aplicativo, utilizou-se a abordagem do Design Participativo, sendo que uma das técnicas utilizadas dentro dessa abordagem foi o Cardsorting, que é uma ferramenta que elabora um modelo mental dos usuários em um determinado espaço de informação (FRISONI E STEIL, 2005). Nela, os participantes ordenam, hierarquizam, nomeiam, agrupam e classificam dados, a partir de um arranjo de cartões (MORAES E SANTA ROSA, 2012). Com base nessas informações, os projetistas analisam e elaboram uma taxionomia dos menus que melhor se adaptam ao mapa mental de seus usuários.

Moraes (2003) destaca algumas vantagens da ferramenta:

Simples e fácil de aprender; barato (o único custo real é o tempo da preparação); rapidamente aplicável, o que permite que mais usuários sejam envolvidos; envolve os usuários no processo do projeto e ajuda a demonstrar que o novo sistema será criado de acordo com as necessidades dos usuários; permite compreender como 'pessoas 


\section{$16^{\circ}$ \\ ERGODESIGN USIHC CINAHPA}

reais' categorizam informação; identifica os prováveis itens que são difíceis de categorizar e achar; e identifica prováveis terminologias que são mal-entendidas.

Desta forma, foram desenvolvidos os cards tendo como referência a linguagem e a atmosfera do ciclismo, a partir do qual foram desenvolvidos os principais elementos pensados para os componentes, comandos e funções do aplicativo, bem como foi feita a elaboração de grupos aos quais os indivíduos poderiam agrupar as opções fornecidas de acordo com sua percepção de semelhança entre os cards. Foi fornecida ainda a possibilidade de inclusão tanto de cards como de grupos aos usuários durante a aplicação da técnica para que formassem a configuração desejada dos elementos.

Para a realização do CardSorting, buscou-se indivíduos levando em consideração o nível de experiência (incluindo a ausência dela) com o uso de aplicativos para dispositivos móveis, o gênero e a idade, sendo desconsiderada apenas a população acima de 60 anos por não se enquadrar no públicoalvo para qual o aplicativo será projetado, pois se distanciam da faixa etária dos estudantes da UFMA e pelo pouco domínio da plataforma mobile.

A aplicação da técnica foi concluída dentro de uma semana. Ao todo, 8 indivíduos participaram desta etapa, que foi realizada com o auxílio da plataforma online de pesquisa com usuários OptimalSort (OPTIMAL WORKSHOP, 2016), a qual viabilizou a aplicação do Cardsorting, bem como a posterior elaboração dos resultados estatísticos.

A partir dos resultados do Cardsorting, desenvolveu-se o mapa de navegação para o aplicativo, que por sua vez, possibilitou a construção de um wireframe, que segundo Teixeira (2014), é um desenho básico da estrutura de determinada interface com o objetivo de demonstrar de forma simplificada como o produto final deve funcionar.

Com a finalização do wireframe, priorizaram-se algumas categorias e foram apontadas algumas tarefas para serem avaliadas durante o teste de usabilidade, sendo estas: tela inicial, a área de cadastro de log in e as opções de relatar um roubo e fazer denúncia. Além disso, simular um tipo de erro $16^{\circ}$ Ergodesign - Congresso Internacional de Ergonomia e Usabilidade de Interfaces Humano Tecnológica: Produto, Informações Ambientes Construídos e Transporte

$16^{\circ}$ USIHC - Congresso Internacional de Ergonomia e Usabilidade de Interfaces Humano Computador

CINAHPA | 2017 - Congresso Internacional de Ambientes Hipermídia para Aprendizagem. e feedback de status ao longo da execução dessas tarefas. A simulação do erro foi realizada durante a tentativa de $\log$ in do participante e foram apresentados feedbacks em mais de um momento ao longo do teste.

Tendo sido selecionadas as tarefas a serem avaliadas, foi desenvolvido um protótipo virtual funcional voltado exclusivamente para a plataforma mobile com a ferramenta de prototipagem online Marvel App (2016), que possibilitou os feedbacks aos usuários ao longo da interação.

Para a avaliação dos resultados do protótipo, realizou-se o teste de usabilidade. Rubin (1993) apud Moraes e Santa Rosa (2012) aponta que esta ferramenta testa funcionalidades em um nível operatório mais detalhado durante a interação dos participantes com a interface ao realizarem tarefas previamente elaboradas.

Para a seleção da amostra do teste de usabilidade, Nielsen (2000) indica que os melhores resultados vêm de avaliações com 5 usuários, pois quanto mais participantes adicionados, menos o pesquisador aprende, já que o mesmo começará a ver alguns resultados sendo repetidos, o que desperdiça recursos e tempo.

Portanto, como garantia de que os resultados pudessem detectar o maior percentual de problemas de usabilidade possível sem o desperdício de recursos descrito por Nielsen, decidiu-se utilizar um número a mais de participantes que a pesquisa técnica indica, totalizando, assim, 6 usuários. Como a Figura 3 apresenta, testes com esse número apontam uma porcentagem maior de problemas (acima de 80\%) de usabilidade que poderiam ser encontrados no objeto da análise. 
$16^{\circ}$ Ergodesign - Congresso Internacional de Ergonomia e Usabilidade de Interfaces Humano Tecnológica: Produto, Informações Ambientes Construídos e Transporte

USIHC CINAHPA

$16^{\circ}$ USIHC - Congresso Internacional de Ergonomia e Usabilidade de Interfaces Humano Computador

CINAHPA | 2017 - Congresso Internacional de Ambientes Hipermídia para Aprendizagem.

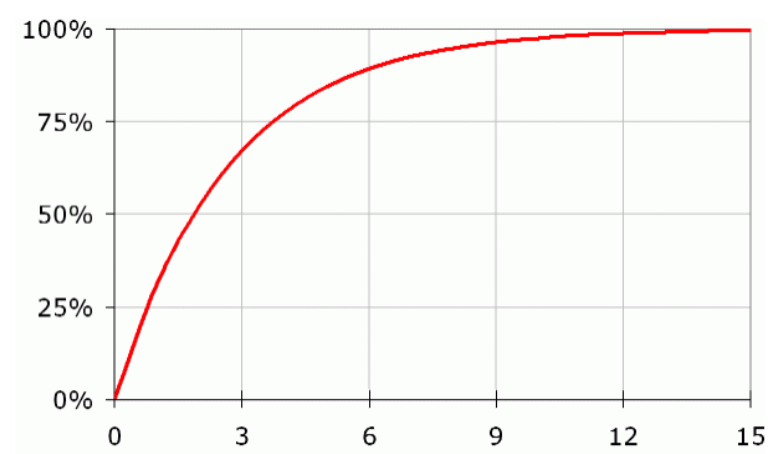

Figura 3: Número de usuários correlacionado com a porcentagem dos problemas de usabilidade encontrados. Fonte: Nielsen (2000).

Além disso, para o teste em questão, a seleção da amostra deve ser representativa a do público-alvo (MORAES E SANTA ROSA, 2012), neste caso, correspondendo aos alunos da Cidade Universitária - UFMA. Dessa forma, para a seleção dos participantes, deu-se prioridade a este nicho, envolvendo indivíduos do sexo masculino, jovens, com idade entre 19 a 29 anos.

Durante o desenvolvimento do teste, optou-se por utilizar como um suporte para os resultados a técnica "Think-Aloud". Nela, o usuário contribui e relata tudo o que pensa, faz ou pretende fazer ao longo da realização das tarefas (MORAES E SANTA ROSA, 2012). Logo, essas avaliações pessoais auxiliaram na construção das análises. A execução das tarefas propostas também foi cronometrada com o intuito de averiguar qual atividade demandava maior tempo para ser executada e qual a média de tempo para conclusão de todas as tarefas propostas.

Ao final do teste de usabilidade, foi apresentado aos participantes a técnica de avaliação de usabilidade SUS - System Usability Scale (BROOKE, 1986), na qual foram apresentadas 10 afirmações acerca do aplicativo onde o indivíduo deveria assinalar se concordava ou discordava em maior ou menor grau com essas declarações, com base em uma escala de 1 a 5, sendo 1 a máxima discordância e 5 a total concordância.

Tendo sido coletadas as respostas do SUS, foi feito o cálculo da média de pontuação obtida através do teste com o aplicativo. De acordo com Brooke (1986), para as afirmações de números ímpares (1, 3, $5,7,9)$, deve-se subtrair 1 da pontuação que $o$ usuário respondeu. Para as afirmações pares $(2,4,6$, 8 e 10), subtrai-se a resposta de 5 . Ou seja, se o usuário respondeu 2 , contabilize 3 . Se o usuário respondeu 4, contabilize 1 . Ao final, todos os valores das dez perguntas são somados e multiplicados por 2.5 , resultando na média de pontuação.

\section{Resultados e discussões}

\subsection{Requisitos projetuais - Briefing}

Por se tratar de uma ferramenta que servirá de suporte para uma atividade diretamente relacionada ao deslocamento e ainda pelas possibilidades tecnológicas oferecidas como geo-localização em tempo real, a plataforma adotada foi voltada para dispositivos mobile, para que o aplicativo esteja disponível aos usuários a qualquer momento, não se prendendo a algumas limitações quanto ao nível de mobilidade presente em outras plataformas. Mas como uma forma de suporte e gerenciamento das informações do aplicativo, pensaram-se nas funcionalidades que podem ser acessadas por outras plataformas, como desktops e notebooks. Essa possibilidade é interessante para oferecer auxílio ao ciclista quando a plataforma mobile se encontrar inviável, como em casos de furto, perda, dentre outros. Assim, tem-se um a forma rápida, fácil e eficiente de preservar e recuperar informações.

O aplicativo tem como principais funções:

a) Fornecer informações úteis e precisas de forma rápida para os usuários em tempo real, como a localização de bicicletários, emergências e demais pontos de suporte.

b) Realizar uma conexão entre os usuários e as autoridades da UFMA, de forma integrada e organizada, a fim de dar celeridade e visibilidade às demandas dos ciclistas.

c) Fortalecer a comunidade ciclista da UFMA a partir do desenvolvimento de uma rede colaborativa entre os próprios usuários do aplicativo, com a possibilidade de interação, promoção de eventos, notificações, dentre outras atividades de cunho social, bem como servir de ponte entre usuários que necessitem de ajuda em situações de 
$16^{\circ}$ Ergodesign - Congresso Internacional de Ergonomia e Usabilidade de Interfaces Humano Tecnológica: Produto, Informações Ambientes Construídos e Transporte

$16^{\circ}$ USIHC - Congresso Internacional de Ergonomia e Usabilidade de Interfaces Humano Computador

emergência e aqueles que podem fornecer algum tipo de suporte.

d) Elaborar uma central de assistência que direciona ou notifica as emergências como furtos e roubos para a equipe de segurança do Campus e demais autoridades cabíveis.

e) Integrar as informações do aplicativo ao Sistema Integrado de Gestão de Atividades Acadêmicas - SIGAA, facilitando o acesso de informações, como recuperação de senhas, comunicações, contatos, dentre outros, além do contato direto com órgãos responsáveis.

\subsection{Cardsorting}

Dentre os 8 participantes, a idade varia entre 17 a 46 anos, sendo 4 homens e 4 mulheres. Foram apresentados 30 cards divididos em 10 categorias para que os participantes da pesquisa pudessem organizá-los da forma que achassem mais adequada.

A partir das associações dos cartões e das categorias obtidas durante a aplicação da técnica, foi possível que a plataforma OptimalSort fornecesse dados e representações estatísticas importantes que definiram a estrutura das informações no aplicativo.

Por meio destas representações, foi possível observar mais claramente os agrupamentos realizados, sendo que os que receberam o maior número associações iguais entre os respondentes foram os cards notícia para a categoria Central de notícias com 8 associações, dúvidas para a seção Help com 7, e os cards mudar foto e privacidade para a categoria Menu da conta, também assinalada por 7 indivíduos (Figura 4).

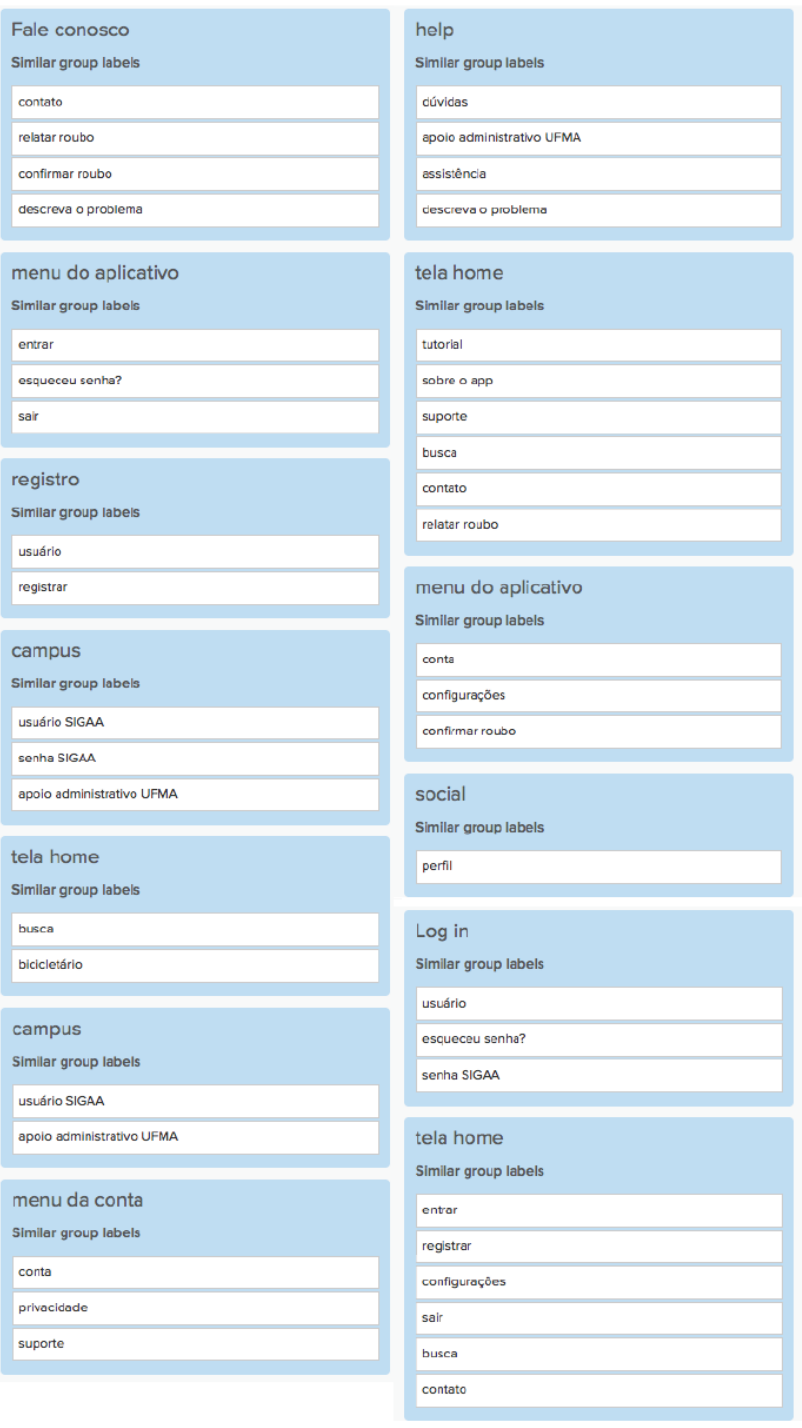

Figura 4: Grupos e seus respectivos cards obtidos através do Cardsorting.

Percebe-se por meio de outras análises que, além das categorias preestabelecidas, houve a inserção por parte dos respondentes de mais uma categoria ao conjunto, denominada "Fale Conosco". Detectou-se a partir dos resultados a necessidade de mudança de alguns termos e a reorganização de alguns elementos, como a mudança do termo Help para Emergência na seção de suporte a imprevistos e emergências, e também a necessidade de criação de uma categoria específica para notícias, o que foi considerado na construção do mapa de navegação. 


\subsection{Mapa de Navegação}

Com base nos resultados obtidos no Cardsorting, elaborou-se o mapa de navegação do aplicativo, estando os principais braços expostos a seguir (Figura 5):

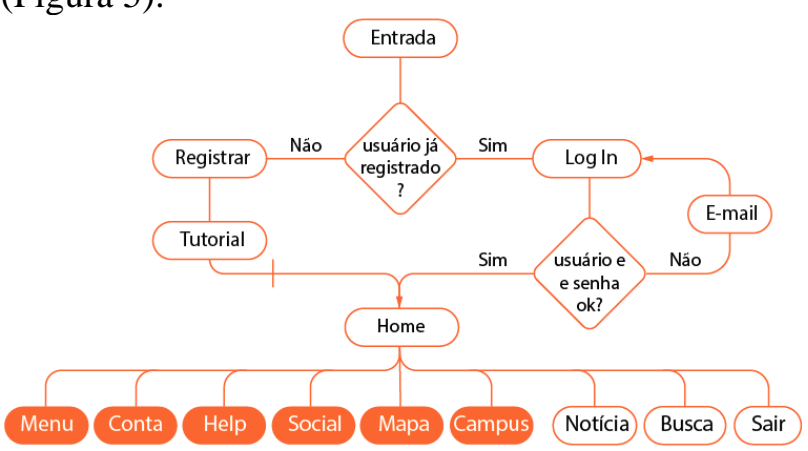

Figura 5: mapa de navegação.

Além das opções, funções e procedimentos comuns a aplicativos em geral, como tela inicia, área de $l o g$ in e registro, o mapa de navegação conta com seis categorias expansíveis que podem se relacionar entre si, de modo a gerar o maior número de opções e comandos, enriquecendo a arquitetura do aplicativo.

Essas categorias expansíveis podem ser consideradas as que agrupam o maior número e as mais

importantes funções oferecidas. Na Figura 5, as categorias expansíveis em outras subcategorias estão representadas por balões preenchidos em laranja e o detalhamento de uma dessas categorias pode ser observado na Figura 6.

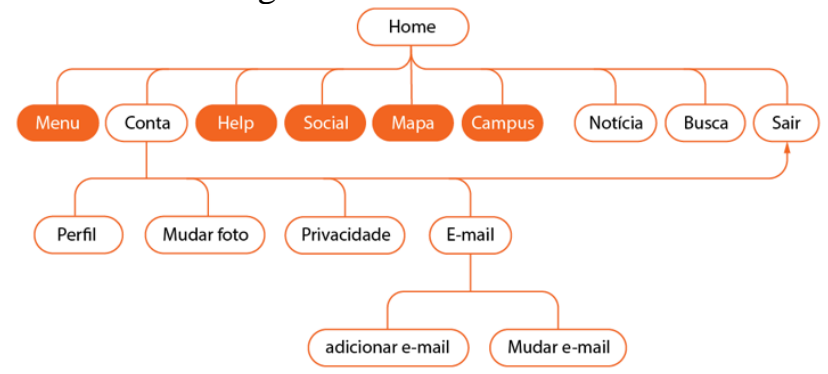

Figura 6: Representação de expansão de categoria.

\subsection{Wireframes}

A partir do mapa de navegação obteve-se o wireframe, que possibilitou a organização dos elementos para a plataforma mobile, levando em consideração aspectos de hierarquização das informações na tela, sua estruturação, peso, relevância e o relacionamento entre outras telas do $16^{\circ}$ Ergodesign - Congresso Internacional de Ergonomia e Usabilidade de Interfaces Humano Tecnológica: Produto, Informações Ambientes Construídos e Transporte

$16^{\circ}$ USIHC - Congresso Internacional de Ergonomia e Usabilidade de Interfaces Humano Computador

CINAHPA | 2017 - Congresso Internacional de Ambientes Hipermídia para Aprendizagem.

aplicativo (BUSARELLO, BIEGING e ULBRICHT, 2013). A seguir, alguns exemplos de telas desenvolvidas na elaboração dos wireframes (Figura 7).

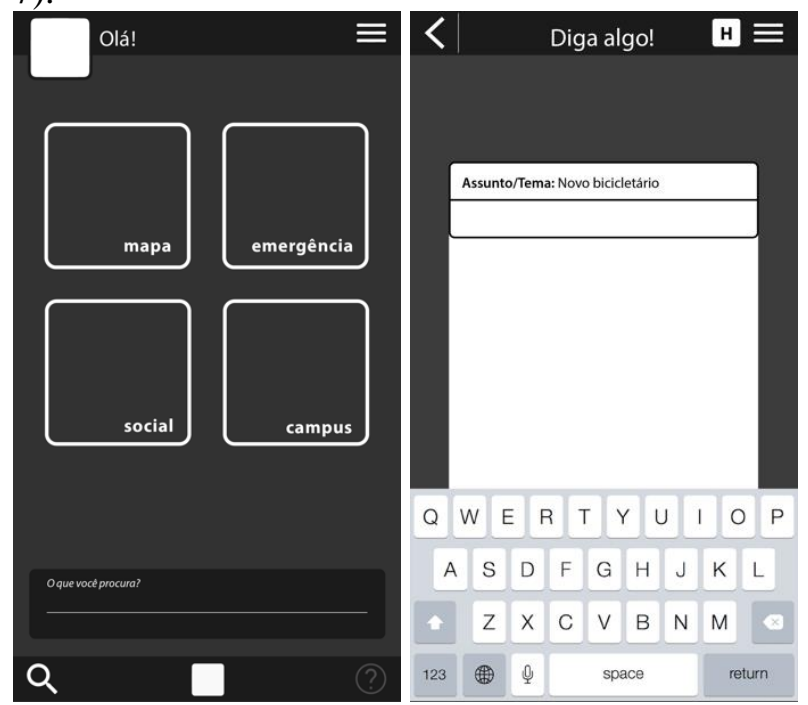

Figura 7: exemplos wireframes desenvolvidos.

Assim como descrito por Busarello, Bieging e Ulbricht (2013), essa representação também serviu como baliza para o teste de usabilidade, onde o wireframe foi utilizado como uma forma de marcação das etapas do processo de interação entre o usuário e o sistema.

\subsection{Protótipo}

Tendo sido aprovada a configuração dos componentes do wireframe, partiu-se para a criação da interface gráfica, levando em consideração aspectos do Design Gráfico, como a simplicidade, unidade e padronização, onde todos os elementos e telas apresentavam algum tipo de correlação visual entre si, reforçada pela linguagem gráfica que remete a atmosfera do ciclismo, apresentando ícones, imagens e a linguagem de comunicação pertinente a esse grupo. Quanto à qualidade estética, teve-se como base uma abordagem associada às bicicletas urbanas retro, reforçada através da paleta de cores e imagens de fundo utilizadas (BUSARELLO, BIEGING e ULBRICHT, 2013).

As considerações da ergonomia de interfaces também estão presentes, como a preocupação com a legibilidade, a consideração da experiência do usuário, a compatibilidade com o usuário e as tarefas 
$16^{\circ}$ Ergodesign - Congresso Internacional de Ergonomia e Usabilidade de Interfaces Humano Tecnológica: Produto, Informações Ambientes Construídos e Transporte

$16^{\circ}$ USIHC - Congresso Internacional de Ergonomia e Usabilidade de Interfaces Humano Computador

do usuário, dentre outros conceitos apresentados por Cybis, Betiol e Faust (2015), que foram reiterados através do design participativo. A seguir, alguns exemplos da interface do aplicativo (Figura 8):
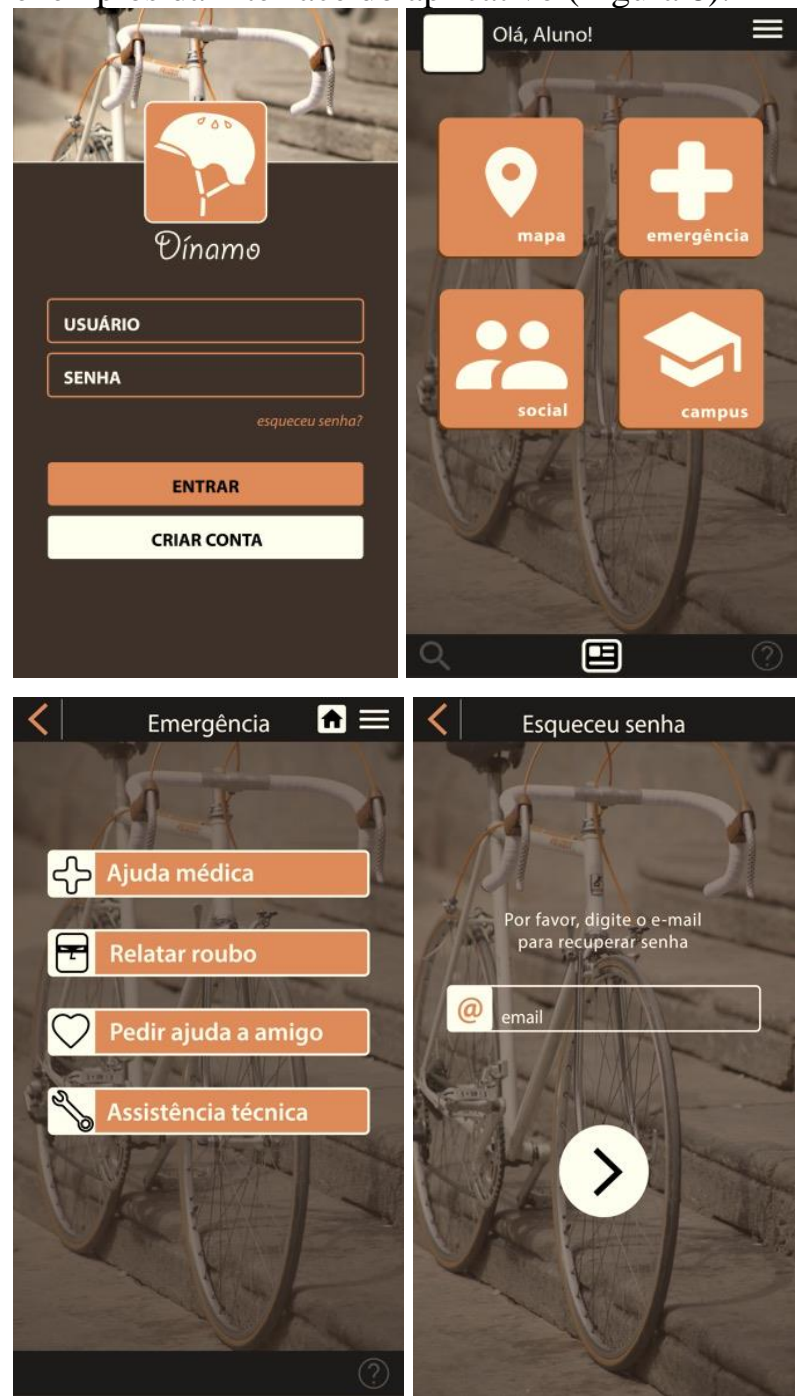

Figura 8: Exemplo das telas do aplicativo Dínamo.

\subsection{Teste de Usabilidade com protótipo}

A média do tempo registrado para as tarefas durante os testes foram (Tabela 1):

\begin{tabular}{|l|l|}
\hline Realização do registro & 33,095 segundos \\
\hline Entrar na conta através da tela de log in & 11,895 segundos \\
\hline Denunciar algo & 27,105 segundos \\
\hline Relatar roubo & 14,741 segundos \\
\hline
\end{tabular}

Tabela 1: Registro de tempo das tarefas.
De forma geral, pode ser observado que as tarefas foram executadas todas em um pequeno intervalo de tempo, o que indica uma rápida compreensão das informações e uma disposição adequada dos elementos, o que foi descrito por dois dos indivíduos durante a aplicação da técnica Thinking Aloud (MORAES E SANTA ROSA, 2012), que consideraram a interface gráfica prática e agradável, com funções intuitivas.

O erro que foi inserido para resolução pelo indivíduo (erro de $\log$ in) foi rapidamente resolvido, tendo sido facilmente identificadas as informações de indicação de erro, além do fácil reconhecimento da fonte do erro propriamente dita. $\mathrm{O}$ tempo máximo para detecção, correção do erro e acesso à tela home percebido entre os indivíduos não passou de 15,03 segundos. O tempo médio para conclusão de todas as atividades foi de 21,7 segundos.

Dentre as 10 questões aplicadas através do questionário de usabilidade, o SUS, 4 delas obtiveram respostas unânimes pelos usuários. Estas foram:

\section{a) Eu acho este aplicativo desnecessariamente complexo. Resposta: Desacordo totalmente.}

b) Eu acho que este aplicativo é fácil de usar. Resposta: Concordo totalmente.

c) Achei o aplicativo muito complicado de usar. Resposta: Desacordo totalmente.

d) Eu precisaria aprender muitas coisas antes que eu possa sair usando este sistema. Resposta: Desacordo totalmente.

Tais resposta unânimes são consideradas positivas para avaliação do aplicativo pois demonstram que a transmissão das informações foi percebida como de forma objetiva e simples, sem demanda de esforço demasiado dos processos cognitivos dos indivíduos, se mostrando uma ferramenta com funções de fácil assimilação e de caráter intuitivo, não necessitando de aprendizagem prévia para sua operação.

Quanto ao restante das afirmativas, os resultados variaram minimamente e quase todos foram
Realização:

w




\section{ERGODESIGN USIHC CINAHPA}

$16^{\circ}$ Ergodesign - Congresso Internacional de Ergonomia e Usabilidade de Interfaces Humano Tecnológica: Produto, Informações Ambientes Construídos e Transporte

$16^{\circ}$ USIHC - Congresso Internacional de Ergonomia e Usabilidade de Interfaces Humano Computador

CINAHPA | 2017 - Congresso Internacional de Ambientes Hipermídia para Aprendizagem.

positivos. Por exemplo, quando dito se a maioria das pessoas poderiam aprender a utilizar o aplicativo rapidamente, $83 \%$ concordaram totalmente, enquanto $17 \%$ apenas parcialmente (Gráfico 1). Por outro lado, a afirmação sobre a inconsistência do aplicativo, apresenta o inverso, ainda que com os mesmos índices: $83 \%$ desacordaram totalmente, enquanto $17 \%$ o faziam parcialmente.

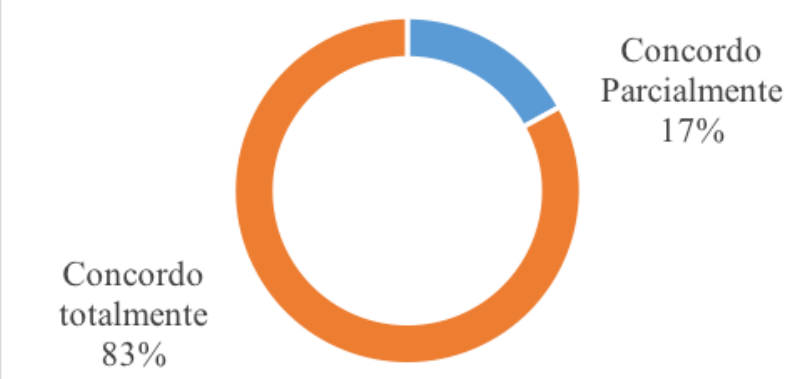

Gráfico 1: respostas quanto a rapidez de aprendizagem de uso.

Com relação à necessidade de um suporte técnico para a utilização do aplicativo, as respostas se dividiram, mas se mantiveram como opiniões favoráveis, ficando: $50 \%$ em desacordo completo e $50 \%$ em desacordo parcial (Gráfico 2).

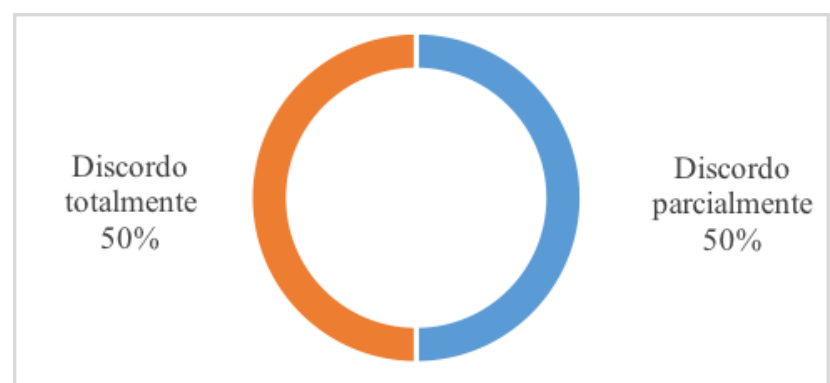

Gráfico 2: Índices referentes à necessidade de um suporte técnico para a utilização do aplicativo.

Com relação à confiança que a interface do aplicativo pressupõe e ao prazer de utilizar o aplicativo com frequência, as respostas foram mais divergentes, ainda que, em grande parte favoráveis (Gráfico 3), considerando que 50\% concordaram com a afirmativa totalmente, $33 \%$ parcialmente e $17 \%$ se mantiveram neutros.

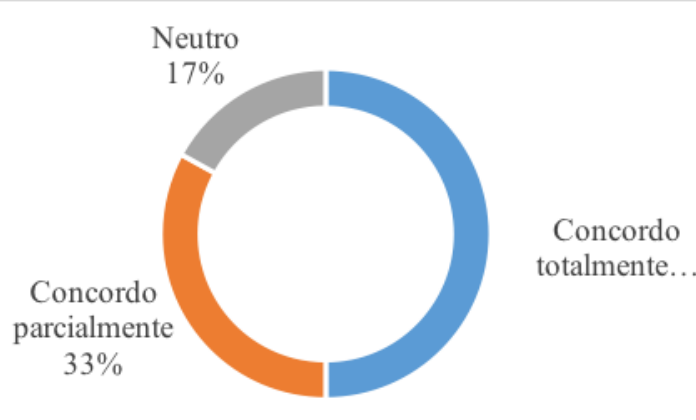

Gráfico 3: Índices referentes a confiança que a interface do aplicativo pressupõe e ao prazer de utilizar o aplicativo com frequência.

Por último, a afirmativa que se refere as funções bem integradas do sistema é de completo acordo por $67 \%$ dos participantes, enquanto $33 \%$ concordam parcialmente (Gráfico 4).

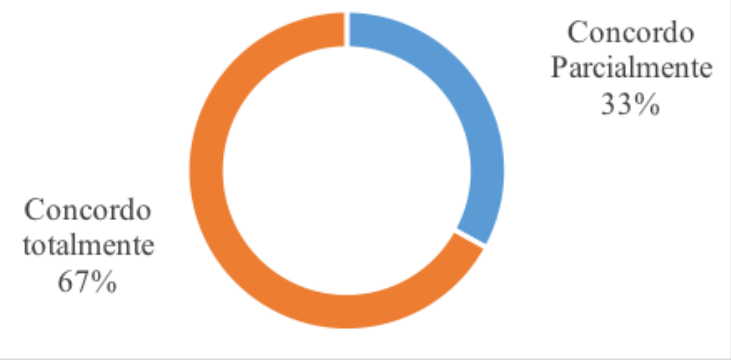

Gráfico 4: Índice dos resultados referentes as funções bem integradas do sistema.

Apesar dos resultados bem favoráveis, com nenhum dos quesitos alcançado níveis insatisfatórios totais ou imparciais, 2 dos 6 participantes realizaram algumas considerações quanto ao uso do aplicativo. De acordo com os dois relatos, durante a função de "realizar uma denúncia", os participantes cogitaram que a opção seria encontrada no menu de emergência, o que não ocorreu. Além disso, um deles ainda apontou que para casos emergentes, opções como estas (denúncia e relatar roubo) seriam mais eficientes se fossem facilmente acessadas e expôs que se elas permanecessem inerente em todas as janelas da interface no canto inferior, elas seriam mais efetivas.

A partir do cálculo dos resultados das respostas de acordo com o que é proposto pela técnica SUS (BROOKE, 1986), obteve-se a tabela com a pontuação de cada participante e a média final 

de Interfaces Humano Tecnológica: Produto, Informações Ambientes Construídos e Transporte

$16^{\circ}$ USIHC - Congresso Internacional de Ergonomia e Usabilidade de Interfaces Humano Computador

CINAHPA | 2017 - Congresso Internacional de Ambientes Hipermídia para Aprendizagem.

obtida pelo aplicativo, apresentada a seguir (Tabela 2).

\begin{tabular}{|c|c|c|}
\cline { 2 - 3 } \multicolumn{1}{c|}{} & $\begin{array}{c}\text { Pontuação por } \\
\text { participante }\end{array}$ & $\begin{array}{c}\text { Pontuação } \\
\text { SUS }\end{array}$ \\
\hline Participante 1 & 36 & 90 \\
\hline Participante 2 & 39 & 97,5 \\
\hline Participante 3 & 40 & 100 \\
\hline Participante 4 & 38 & 95 \\
\hline Participante 5 & 35 & 87,5 \\
\hline Participante 6 & 36 & 90 \\
\hline & $\begin{array}{c}\text { Índice de satisfação e } \\
\text { usabilidade }\end{array}$ & $\mathbf{9 3 , 3 3}$ \\
\cline { 2 - 3 } & &
\end{tabular}

Tabela 2: Resultados do SUS.

Os resultados apresentam um alto índice de satisfação e usabilidade, comprovando a eficiência da abordagem participativa e a consistência e eficiência do aplicativo.

\section{CONCLUSÕES}

Os resultados demonstram que os objetivos propostos para o teste de usabilidade foram alcançados. O tempo para a realização das tarefas também foi satisfatório, tendo uma média de duração inferior a 30 segundos.

A abordagem do design participativo foi um elemento-chave no desenvolvimento deste trabalho, por meio do qual foram obtidas guidelines importantes que contribuíram para o sucesso do teste de usabilidade, como o uso da técnica de CardSorting para a estruturação da informação. Contudo, como foi indicado pelos usuários por meio da técnica Thinking Aloud, são necessários maiores estudos onde, os demais elementos do aplicativo não embarcados neste momento durante o teste de usabilidade sejam validados e as possíveis incompatibilidades apontadas sejam sanadas.

Apesar da atual falta de infraestrutura e dos poucos incentivos, é necessário pensar cada vez mais nos ciclistas estudantes da UFMA, pois a adoção da bicicleta para locomoção é uma tendência global que inevitavelmente chegará em São Luís. E desenvolver uma estrutura, seja ela física ou virtual, pode contribuir para que essa transição se dê de forma mais fluida e mais rápida. A proposta de aplicativo aqui apresentada visou reforçar esse pensamento e destacou a importância da consideração da participação do usuário ao longo da projetação de plataformas voltadas para os ciclistas, de modo que o aplicativo Dínamo possa se unir a outras propostas já existentes ou que estejam emergindo no Campus para que a mobilidade seja mais eficiente.

O seu diferencial em relação a outras ferramentas atualmente disponíveis é justamente o pensamento de integração com as ferramentas presentes em desenvolvimento dentro da Universidade, de modo que gradativamente essas ferramentas se consolidem e comuniquem entre si para fornecer serviços voltados para as reais necessidades dos ciclistas da UFMA.

\section{REFERÊNCIAS}

BROOKE, J. SUS - A quick and dirty usability scale. User Information Architecture Advanced Development Group, Reading, 1986. Disponível em: <https://hell.meiert.org/core/pdf/sus.pdf>. Acesso em: 12 mar. 2017.

BUSARELLO, R. I.; BIEGING, P.; ULBRICHT, V. R (Org.). Mídia e educação: novos olhares para o aprendizado sem fronteiras. São Paulo: Pimenta Cultura, 2013. 172 p. ISBN: 978-85-66832-02-0.

CONFEDERAÇÃO NACIONAL DA INDÚSTRIA. Vá de bicicleta. Brasília, 2010. Disponível em: <http://www.cni.org.br/portal/main.jsp?lumPageId= FF8080812A602D81012A63785F53155D\&lumI=ge staodoconhecimento.service.noticia.details\&lumIte $\mathrm{mId}=\mathrm{FF} 8080812 \mathrm{CA} 8 \mathrm{C} 986012 \mathrm{CA} 9 \mathrm{ADF} 5382 \mathrm{~B} 56>$. Acesso em: 30 mar. 2016.

CYBIS, W.; BETIOL, A. H.; FAUST, R.

Ergonomia e usabilidade: conhecimentos, métodos e aplicações. São Paulo: Novatec, 2007.

CYBIS, W.; BETIOL, A. H.; FAUST, R.

Ergonomia e usabilidade: conhecimentos, métodos e aplicações. São Paulo: Novatec, 2015. 496 p. ISBN: 857522459X.

FRISONI, B. C.; STEIL, V. Como estruturar melhor a área de contato com o usuário? A utilização da

Técnica de Cardsorting para desenvolver a estrutura do website do Núcleo de Inovação em design da Cadeia Têxtil. In: CONGRESSO

INTERNACIONAL DE ERGONOMIA E 
$16^{\circ}$ USIHC - Congresso Internacional de Ergonomia e Usabilidade de Interfaces Humano Computador

CINAHPA | 2017 - Congresso Internacional de Ambientes Hipermídia para Aprendizagem.

USABILIDADE, DESIGN DE INTERFACES E INTERAÇÃO HUMANO-COMPUTADOR, 5., 2005, Rio de Janeiro. Anais... Rio de Janeiro: PUCRio, 2005. Disponível em:

$<$ http://www.vivisteil.com.br/articles/card-sortingartigo-frisoni-steil-5USIHC.pdf>. Acesso em: 28 ago. 2016.

GMAPS-RADIUS, Londres: 2017. Disponível em: <http://obeattie.github.io/gmaps-

radius $/$ ?radiusInput $=125 \&$ unitSelector $=$ mi $\& l a t=45.7$

$03965 \& \operatorname{lng}=-11.968768 \& z=6 \& u=m i \& r=5>$. Acesso em: 01 mar. 2017.

GOOGLE Play. Mountain View: Google Inc., 2017. Disponível em: <https://play.google.com/store>. Acesso em: 02 mar. 2017.

GUIMARÃES, L. B. de M. Análise Macroergonômica do Trabalho AMT: modelo de implementação e avaliação de um programa de ergonomia na empresa. In: GUIMARÃES, L. B. de M. (Org.). Macroergonomia: colocando conceitos em prática. 1. ed. Porto Alegre: UFRGS/FEENG, 2010. v.1.

IIDA, I. GUIMARÃES, L. B. M. Ergonomia: projeto e produção. 3. ed. São Paulo: Blucher, 2016.

LINDNER, L. H.; ULBRICHT, V. R.; PALAZZO, A. M. Análise da interface padrão do Oxwall como plataforma de rede social. Revista Brasileira de Design da Informação / Brazilian Journal of Information Design. São Paulo. v. 11, n. 1 [2015], p. 86 - 104, ISSN 1808-5377.

MARVEL App. Londres: 2016. Disponível em: <https://marvelapp.com>. Acesso em: 20 ago. 2016.

MORAES, A. de; SANTA ROSA, J. G. Design participativo, técnicas para inclusão de usuários no processo de ergodesign de interfaces. 1 . Ed. Rio de Janeiro: Rio Book’s, 2012.

NIELSEN, J. Why you only need to test with 5 users. [S.1.]: Nielsen Norman Group, 2000.

Disponível em:

$<$ https://www.nngroup.com/articles/why-you-onlyneed-to-test-with-5-users/>. Acesso em: 25 ago. 2016.
OPTIMALSORT. Wellington: Optimal Workshop, 2016. Disponível em:

<https://www.optimalworkshop.com/optimalsort>. Acesso em: 30 jun. 2016.

\section{PREFEITURA DE SÃO LUÍS. Prefeito Edivaldo} lança edital de licitação que transformará transporte urbano de São Luís. São Luís, 2016. Disponível em:

<http://www.saoluis.ma.gov.br/subportal_noticia.as p?id_noticia=16963>. Acesso em: 30 mar. 2016.

REIS, L. O. dos. Gestão do design para o planejamento estratégico macro do sistema de bicicletas na Universidade Federal do Maranhão. 2014. 52 f. Trabalho de Conclusão de Curso (Graduação)- Universidade Federal do Maranhão, São Luís, 2014.

SISTEMA FIRJAN. O custo dos deslocamentos nas principais áreas urbanas do Brasil. Rio de Janeiro: FIRJAN, 2015a. Disponível em: <http://www.firjan.com.br/lumis/portal/file/fileDow nload.jsp?fileId=2C908A8F4F8A7DD3014FB26C8 F3D26FE\&inline=1>. Acesso em: 29 mar. 2016.

$O$ custo dos deslocamentos nas áreas metropolitanas: Estado do Maranhão. Rio de Janeiro: FIRJAN, 2015b. Disponível em: <http://www.firjan.com.br/lumis/portal/file/fileDow nload.jsp?fileId=2C908A8F4F8A7DD3014FBDD41 40834A9\&inline=1 >. Acesso em: 29 mar. 2016.

SPINUZZI, C. The methodology of participatory design. Applied Theory, [Fairfax], v. 52, n. 2, p. 163-174 Society for Technical Communication, 2005. Disponível em:

<https://repositories.lib.utexas.edu/bitstream/handle/ 2152/28277/SpinuzziTheMethod ologyOfParticipatoryDesign.pdf> . Acesso em: 20 ago. 2016.

TEIXEIRA, F. Introdução e boas práticas em UX Design. São Paulo: Casa do Código, 2014. 